САВРУЦКАЯ Елизавета Петровна - доктор философских наук, профессор; профессор кафедры философии, социологии и теории социальной коммуникации Нижегородского государственного лингвистического университета им. Н.А. Добролюбова (603155, Россия, г. Нижний Новгород, ул. Минина, 31a; savrutsk@mail.ru)

УСТИНКИН Сергей Васильевич - доктор исторических наук, профессор; декан факультета международных отношений, экономики и управления, профессор кафедры международных отношений и политологии Нижегородского государственного лингвистического университета им. Н.А. Добролюбова (603155, Россия, г. Нижний Новгород, ул. Минина, 31а); директор Приволжского филиала Федерального научно-исследовательского социологического иентра РАН (603000, Россия, г. Нижний Новгород, пер. Холодный, 4; sv.ustinkin@gmail.com)

\title{
ИСТОРИЧЕСКАЯ ПАМЯТЬ КАК ФАКТОР НАЦИОНАЛЬНОЙ БЕЗОПАСНОСТИ
}

\begin{abstract}
Аннотация. Статья посвящена исследованию исторической памяти как феномена духовной культуры, способствующего укреплению духа русского народа, его единению вокруг государства, сохранению культурного наследия многонациональной России. Закрепленная в культурных кодах и социальных механизмах регламентации коммуникационных процессов и трансляции социокультурного опыта поколений историческая память сохраняла в массовом сознании российского суперэтноса социально значимую информацию, обеспечивая тем самым преемственность в историко-культурном развитии русской цивилизации.

Ключевые слова: историческая память, Русская православная церковь, государство, русская цивилизация, культурные коды, социальные механизмы, национальная безопасность, преемственность, коммуникационные процессы
\end{abstract}

« амять истории», «историческая память», «память сердца», «память как феномен сознания, души и сердца»... Богатство русского языка передает многообразие смыслов и оттенков, возникающих в различных контекстах жизненного мира человека.

В философии память рассматривается как способность организма сохранять и воспроизводить информацию о внешнем мире и о своем внутреннем состоянии для дальнейшего ее использования в процессе жизнедеятельности человека. В социально-гуманитарном знании, несмотря на существование различных подходов к рассматриваемому феномену, всегда центральной проблемой памяти считалась способность системы к накоплению, переработке, хранению и передаче социально и культурно значимой информации, необходимой для функционирования общества. В ходе истории социокультурный опыт человечества фиксировался в исторической памяти народов с помощью культурных кодов как средств и механизмов социального наследования, включающих язык, искусство и другие знаковые системы, а также во всем многообразии предметно-вещественной среды материальной и духовной культуры, в традициях, обычаях, обрядах, праздниках, нормах поведения и т.д. Культурные коды как закодированная в определенной форме деятельности, символов или знаков информация способствовали идентификации смыслов и значений коллективного или индивидуального «я» с комплексом подобных признаков «другого». Как система знаков, не имеющих предметного значения, а потому выступающих в форме символов, культурные коды в ходе историко-культурного развития общества играли роль способов хранения и передачи информации.

Этническое многообразие населения России несло с собой и разнообразие текстов, закрепляемых в национальных культурных кодах, т.е. языках, религиях, исторически сложившихся нормах поведения, способах регламентации 
коммуникационных процессов. Культурные коды играли особую роль в упорядочении общественных процессов и сохранении целостности и этнокультурной уникальности российского социума. Язык, символы и другие знаковые системы, наряду с традициями, обычаями и обрядами, архитектурными сооружениями и произведениями искусства сакрального характера, а также нормами и правилами поведения, составляли комплекс культурных кодов этносов и являлись ведущими характеристиками этнокультурной идентичности. Культурные коды играли определяющую роль как в закреплении и воспроизводстве ведущих признаков этнокультурной идентичности и национальных культур, так и в обеспечении духовной преемственности и сохранении целостности социума, структурировании коммуникативного пространства цивилизаций.

В отличие от естественных языков, имеющих протяженность в истории (Ю. Лотман), культурные коды являются моделью коммуникации и своего рода искусственным языком, сохраняющим заложенные в нем значения и смыслы на столь долгое время, пока «живы» обозначающие их и соответствующие им культурные коды - будь то язык или другие знаковые системы, а также определенные виды коммуникативного действия (традиции, обычаи, обряды, праздники и т.д.). Обеспечивая адекватность организации вербальных и невербальных систем историко-культурной традиции или установленной нормы отношений, культурные коды удерживали в памяти истории национально-культурное своеобразие народов. Культурные коды транслировали соответствующее понимание символов и образов национальных культур на новые поколения, являясь, тем самым, важнейшим механизмом духовной преемственности и этнокультурной идентичности, а также условием сохранения целостности социумов.

В условиях глобализации, отягченных обострением международных отношений, войнами на Ближнем Востоке и в Центральной Азии, а также глобальным миграционным кризисом, грозящим перерастанием этноконфессиональных противоречий в межцивилизационные конфликты [Бердяев 2016], произошла глубокая трансформация системы этнокультурных кодов. Сущность этой трансформации заключается в том, что многие культурные коды, веками накапливающие и обеспечивающие социальную преемственность в историко-культурном развитии народов, постепенно теряли свою определяющую роль в сохранении и воспроизводстве ведущих признаков этнокультурной идентичности и этнокультурной картины мира. В процессах конструирования новой «расширенной объективно-виртуальной реальности» [Макеев 2017] ранее сложившиеся и ставшие в значительной степени стереотипными традиционные эталоны повседневности, а также нормы регламентации коммуникационных процессов заменяются языковыми и символическими моделями. Унификация управления культурными кодами в условиях широкого распространения инструментальных моделей массовой культуры способствует размыванию стандартов национальных культур, в результате чего сужаются возможности историко-культурного наследования их определяющих признаков.

Разрушение системы этнокультурных кодов коммуникационного пространства этносов неминуемо ведет к кризису этнокультурной идентичности и трансформации социальных механизмов сохранения и воспроизводства социального опыта поколений, нанося невосполнимый ущерб процессам социокультурной преемственности. В этой связи возникает достаточно трудно разрешимая дилемма, связанная с исследованием проблемы разрушения связи между образами исторической памяти и этнокультурными кодами, вызванного унификацией управления системами культурных кодов в условиях глобализации. Если культурные коды - это система знаков, не имеющих предметного значения, в силу чего они всегда выступают в форме символа, то обратная сторона этой 
системы, т.е. ее предметно-практическое и духовно-нравственное значение, есть не что иное, как сама история культуры народов. Создаваемая картина мира, прежде всего ее лингвосоставляющая часть, удерживает в активном состоянии сформировавшиеся в сознании людей образы мира. Благодаря культурным кодам эти образы определяют границы самоидентификации народов, создают комплекс духовных практик, являющихся основанием такого величественного явления духовной культуры, как историческая память, удерживающая в многообразии культурно-кодовых систем основные исторические события прошлого. Данный аспект понимания исторической памяти близок к понятию памяти коллективной, тесно связанной с «формированием индивидуальной и коллективной идентичности, проблемами легитимности политических режимов, идеологического манипулирования, с моральными аспектами прошлого» ${ }^{1}$.

Уничтожающая сила времени меркнет перед силой и устойчивостью исторической памяти, которая благодаря текстам как многосмысловым образованиям, по мнению Ю. Лотмана, обладает способностью не только «сохранять память» «о своих предшествующих контекстах», но и быть генератором новых смыслов. «Это создаваемое текстом вокруг себя смысловое пространство вступает в определенные соотношения с культурной памятью (традицией), отложившейся в сознании аудитории, обретая новую семиотическую жизнь» [Лотман 1996: 21 22]. Историческая память, запечатленная в языке, обеспечивает связь прошлого и будущего через настоящее. Л.Н. Гумилев рассуждает о том, что прошлое - это не «личное переживание» и не мечта. «Ибо настоящее - только момент, мгновенно становящийся прошлым» [Гумилев 2002: 408]. Все неповторимое и прекрасное в человеческой истории при определенных обстоятельствах, по мнению Л.Н. Гумилева, исчезает, гибнет. «Но против гибели выступает Память; а коллективная память этносов - это и есть история культуры» [Гумилев 2002: 415]. Явление прошлого в системе культуры настоящего является знаком не только другого времени, но и символом той связи, которая обеспечивает эту связь [Гумилев 2003: 419].

Роль этнокультурных кодовых систем в сохранении исторической памяти и национальной культуры народов сталкивается с большими трудностями в эпоху глобализации, характерным признаком которой является так называемый феномен унификации, втягивающий в свою орбиту «одинаковости» не только моду, средства связи, элементы предметно-вещественной среды, но и языковые модели, формы поведения, системы ценностей. В этих условиях основная нагрузка по сохранению признаков этнокультурной идентичности, духовной преемственности, исторической памяти ложится на язык. Увеличение роли последнего в сохранении национальных образов мира связано с тем, что по мере углубления процессов трансформации культурно-коммуникативного пространства народов происходит вытеснение традиционных систем этнокультурных кодов новыми информационно-коммуникативными технологиями, что, естественно, создает колоссальные трудности в сохранении и трансляции образов исторической памяти в ряду поколений.

Особенности современных коммуникационных процессов способствуют формированию новых образов реального мира, изменяют содержание и направленность ценностного сознания человека. В жизненном пространстве человека прочное и все увеличивающееся в общем объеме времени место занимают системы симулякров и других символических знаков виртуальной реальности. В мире повседневности человека увеличивается доля спроектирован-

\footnotetext{
${ }^{1}$ Социальная философия: словарь (сост. и ред. В.Е. Кемеров). Т. Х. 2-е изд. 2006. М.: Академический Проект; Екатеринбург: Деловая Книга. С. 328-331.
} 
ных сообщений, получаемых индивидом по различным каналам СМИ и глобальной сети. По словам Э. Тоффлера, вздымающиеся все выше и выше волны кодированной информации [Тоффлер 2004: 189] обрушиваются на человека, в корне изменяя его отношение к окружающему миру, стирая в сознании личности образы исторической памяти, разрушая богатство национальных языков и культур. Виртуальная коммуникация качественно изменяет веками складывающиеся и закрепленные в языке как системы отношений между людьми, так и социальные механизмы, т.е. культурные коды, трансляцию социокультурного опыта поколений. Под влиянием изменений в системе современных социокультурных условий и международных событий проблемы языка все больше приобретают политический контекст, свидетельством чего являются события на Украине. В контексте политической доктрины запрещения русского языка на всех уровнях делового и повседневного общения бывший президент Украины в арсенал средств борьбы с Россией внес язык. Триада «Армия. Вера. Язык» рассматривалась в качестве главного фронта, уничтожающего «русскость» во всех формах ее проявления [Савруцкая, Семенов 2018].

Очевидно, что языковая реальность все более начинает занимать лидирующие позиции в формировании жизненного мира человека, порождая новый тип коммуникативного поведения, новую конфигурацию культурно-коммуникативного пространства современной цивилизации. Как одна из важнейших форм сохранения и трансляции интерсубъективного опыта, современная языковая картина мира испытывает на себе большое влияние новых информационнокоммуникативных технологий, оказывающих многостороннее воздействие не только на возможности получения знаний, но и на процессы трансформации привычных методов обучения и воспитания, обеспечиваемых институтами образования и семьи [Савруцкая и др. 2019: 73-102]. Вместе с тем этноязыковая картина мира в наибольшей степени способствует закреплению национальных кодов, сохраняя тем самым мир культуры и коллективной памяти.

Осуществляемая в системе языковых средств связь настоящего с прошлым и будущим открывает смыслы, которые, трансформируясь под влиянием изменений мира, оберегают вместе с тем то духовное содержание, которое обеспечивает воздействие прошлого на настоящее, способствуя сохранению исторической памяти как духовного стержня личности гражданина своего отечества, представителя культуры своего народа [Бондарева, Савруцкая, Устинкин 2019: 68]. И в этом проявляется историзм речевой культуры, которая как особая форма социальности и сохранения историко-культурных смыслов является важнейшим средством обеспечения связи времен и поколений. Эта особенность языка в контексте его рассмотрения как культурного кода и механизма сохранения уникальности историко-культурных традиций, насчитывающего тысячелетие существования многонационального, пограничного между Западом и Востоком Государства российского [Никонов 2014: 18-22], позволяет считать рассматриваемый феномен условием возможности сохранения и воспроизводства российской цивилизации. В языке находит выражение и закрепляется этническая картина мира, формируется логика этноса, определяются основания и критерии этнокультурной идентичности. Вносимые процессами глобализации коррективы в трансформацию кодовых систем увеличивают роль языка в обеспечении целостности и устойчивости культурно-коммуникативного пространства этносов, в связи с чем проблемы языка все больше вписываются в политический контекст, обретая формат лингвистической безопасности в общей парадигме национальной безопасности страны ${ }^{1}$.

\footnotetext{
${ }^{1}$ Концепция национальной безопасности Российской Федерации.
} 
Определяющая роль языка в формировании национального характера и сохранении национальной памяти народа в его историко-культурном развитии определяется неразрывным единством реальных исторических событий и их сохранением в этноязыковой картине мира. В замечательном труде В. Кожинова «История Руси и русского слова» отмечается, что в отечественной истории слово всегда играло неоценимую роль. «И бытие, и сознание любого народа, - пишет автор, - уходят своими корнями в “доисторические” времена, длившиеся тысячелетиями. Это с очевидностью предстает, например, в содержании русского героического эпоса - богатырских былин, которые являют собой ценнейшую часть начальной стадии развития национальной культуры». Эпос, по мнению Кожинова, является наиболее ранним воплощением начавшейся истории народа, воплощением ее «в слове и, если ставить вопрос более широко, в культуре». В понятии «героический эпос» запечатлены понятия таких реальностей истории Руси, как культура, государственность и, наконец, «история в собственном смысле слова» [Кожинов 2001: 75-76].

В силу этих особенностей современных цивилизационных процессов и установления нового мирового порядка проблема исторической памяти рассматривается нами в системе факторов национальной безопасности, приобретая особое жизненно важное значение в контексте проблем национальной молодежной политики. В работе с молодежью очень важна матрица отечественных ценностей национальной культуры, политики, обороны страны, ее культуры. Молодежь должна иметь четкие представления о том, зачем, во имя чего она живет, получает образование, осуществляет карьеру. При этом очень важно, чтобы личностную картину видения своего жизненного пути представители молодого поколения соотносили с ценностями своего народа, своей страны. И в том и в другом случае при их сравнении происходит наложение одной картины на другую, в результате чего образуется комплекс ценностей, нравственный аспект которых вырастает из положений доктрины национальной безопасности. Это идеальный вариант общей картины ожидаемых результатов образовательной и воспитательной деятельности по подготовке молодежи к самостоятельной взрослой жизни.

Но!.. Реальные условия современных цивилизационных процессов, диктуемые реальным контекстом в сфере международных событий, в области политики, культуры и экономики внутри страны, историко-культурные, национальноэтнические, территориальные и климатические ее особенности конкретизируют цели, задачи, возможности и механизмы осуществления стратегии развития России. Нельзя не принимать во внимание и сдвиг массового сознания российской молодежи в сторону усиления прагматического подхода в оценке общественных явлений и процессов, степень их соответствия или несоответствия личностным интересам и потребностям.

Возникает вопрос: что в современной российской действительности является матрицей для развития культурных проекций на ближайшее и отдаленное будущее постглобализационного этапа развития русской цивилизации? К примеру, образ Мацуева - великого музыканта, патриота, воспитателя, футбольного фаната, участника проекта «Синяя птица»... Заслуживает большого внимания в плане понимания необходимости тщательной работы над сохранением исторической памяти нашего народа глубокий аналитический обзор особенностей современного состояния массового сознания российского суперэтноса, осуществленный К.Г. Шахназаровым в программе «Вечер с Владимиром Соловьевым» 1-го сентября 2017 г. В частности, К. Шахназаров обратил внимание на такую крайне неприятную черту российского национального самосознания, как привычка постоянно прибедняться в оценке истории своей страны, 
своих социокультурных особенностей и вклада русской национальной культуры в общемировую культуру. Мы забываем, по словам К. Шахназарова, что только за последние 500 лет мы сбросили польское владычество, разбили Фридриха II, Карла XII, Наполеона, Гитлера. Россия - это единственная страна, которая в короткие сроки стала лидером новых технологий. В отличие от американца, для которого все американское - это fine, для синдрома русского национального самосознания характерно забвение того, что за 100-150 лет русский человек прошагал от границ Московского княжества до Дальнего Востока, объединил вокруг русских многочисленные народы, населявшие огромные территории Евразийского континента. А мы все прибедняемся с оглядкой на Европу и Северную Америку. Стоит ли удивляться тому, что Россию не любят, задает риторический вопрос К. Шахназаров. Нас любили в $90-е$ гг. XX в.; Китай в 70-е гг. этого же века западные страны буквально боготворили, но именно в это время эта страна была на крайне низком уровне экономического развития. Корни русофобии К. Шахназаров видит в национальной черте постоянной недооценки своего значения в мировой истории. К сожалению, идеи замечательного российского мыслителя и одного из ярчайших представителей российского киноискусства не получили дальнейшего развития в дискуссиях и учебно-воспитательных программах по формированию образов исторической памяти при работе с молодежью. А ведь очень многие исследования академика Б.А. Рыбакова, В.О. Ключевского, идеи Н. Бердяева. Ф.М. Достоевского, А.С. Пушкина, А. Блока и многих других великих отечественных мыслителей могли быть предметом обсуждения самой широкой общественности, в первую очередь молодых поколений [Ключевский 1987; Рыбаков 1987; Пушкин 1981; Бердяев 2016]. К сожалению, в информационном плане средства массовой информации в политических ток-шоу приоритет отдают польским, украинским, прибалтийским, да и своим собственным русофобам с их постоянными патологически ненавистническими высказываниями в адрес всего того, что связано с русским миром, российской цивилизацией и лицами, ее персонифицирующими.

Таким образом, исследование уникальности русской цивилизации под углом зрения рассмотренных выше факторов способствует пониманию места и роли русского государства и православной церкви в обеспечении единства и сохранения российского социума. Факты истории, запечатленные в образах массового сознания населения страны и закрепленные в ее культурных кодах, в предметно-вещественной среде материальной и духовной культуры, в текстах как «смыслообразующих устройствах» (Ю.М. Лотман), традициях и других знаках памяти, обретших характер культурных символов, становятся своеобразным пантеоном исторической памяти. Как неотъемлемый элемент самосознания и ментальности народа, его национальной и гражданской идентичности память истории народа священна (Д.С. Лихачев). Она воспроизводит непрерывность и преемственность социального бытия, обеспечивая тем самым нерасторжимую связь прошлого, настоящего и будущего. Историческая память - это важнейший социокультурный механизм сохранения традиционных ценностей русской цивилизации: государства, православной веры, семьи, оснований этнокультурной идентичности русского народа и в целом российского суперэтноса.

\section{Список литературы}

Бердяев Н.А. 2016. Судьба России. СПб: Азбука. 416 с.

Бондарева С.К., Савруцкая Е.П., Устинкин С.В. 2019. Экология языка в проблемном поле современных глобализационных процессов. - Власть. Т. 27. № 2. C. 66-74. 
Гумилев Л.Н. 2002. Этногенез и биосфера Земли. СПб: Азбука-классика. 608 с.

Гумилев Л.Н. 2003. Искусство и этнос. - Собрание сочинений. В 12 т. СПб: СЗКЭО «Кристалл». Т. 9.620 с.

Ключевский В.О. 1987. Сочинения в девяти томах. Т. І. Курс русской истории. М.: Мысль. Лекция IV. С. 78-90 с.

Кожинов В.В. 2001. История Руси и русского слова. Опыт беспристрастного исследования. М.: ЭКСМО-Пресс. 512 с.

Лотман Ю.М. 1996. Внутри мыслящих миров. Человек - текст - семиосфера история. М.: Языки русской культуры. 464 с.

Макеев С.Н. 2017. Феномен социального общения в пространстве расширенной объективно-виртуальной реальности: автореф. дис. ...к.филос.н. Нижний Новгород. $19 \mathrm{c}$.

Никонов В.А. 2014. Русская матрица. М.: ООО «Русское слово - учебник». 992 c.

Пушкин А.С. 1981. Письмо Чаадаеву (19 октября 1836). - Собрание сочинений. В 10 т. М.: Правда. Т. Х. С. 218-219 с.

Рыбаков Б.А. 1987. Язычество Древней Руси. М.: Наука. 783 с.

Савруцкая Е.П., Жигалев Б.А., Никитин А. В., Устинкин С.В. 2019. Современный мир и молодежь: иенности, риски, угрозы: монография. Н. Новгород: Изд-во НГЛУ. Т. 1.268 с.

Савруцкая Е.П., Семенов Д.В. 2018. Проблемы лингвистической безопасности в коммуникативном пространстве русского мира. - Языковая политика $u$ лингвистическая безопасность. Н. Новгород: Изд-во НГЛУ. С. 353-359.

Тоффлер Э. 2004. Шок будущего. М.: АСТ. 557 с.

SAVRUTSKAYA Elizaveta Petrovna, Dr.Sci. (Philos.), Professor; Professor of the Chair of Philosophy, Sociology and Theory of Social Communication, Dobroljubov State Linguistics University of Nizhny Novgorod (31a Minina St, Nizhny Novgorod, Russia, 603155; savrutsk@mail.ru)

USTINKIN Sergei Vasil'evich, Dr.Sci. (Hist.), Professor; Dean of Faculty of International Relations, Economics and Management, Professor of the Chair of International Relations and Political Science, Dobroljubov State Linguistics University of Nizhny Novgorod (31a Minina St, Nizhny Novgorod, Russia, 603155); Director of Volga branch of the Federal Center of Theoretical and Applied Sociology, Russian Academy of Sciences (4 Holodny Lane, Nizhny Novgorod, Russia, 603000; sv.ustinkin@gmail.com)

\section{HISTORICAL MEMORY AS A FACTOR OF NATIONAL SECURITY}

\footnotetext{
Abstract. The article is devoted to the study of historical memory as a phenomenon of spiritual culture, contributing to the strengthening of the spirit of the Russian people, their unity around the state, preservation of the cultural heritage of multinational Russia. Fixed in cultural codes and social mechanisms for regulating communication processes and transmitting the socio-cultural experience of generations, historical memory retained socially significant information in mass consciousness of the Russian super-ethnos, thereby ensuring continuity in the historical and cultural development of Russian civilization.

Keywords: historical memory, Russian Orthodox Church, state, Russian civilization, cultural codes, social mechanisms, national security, continuity, communication processes
} 